
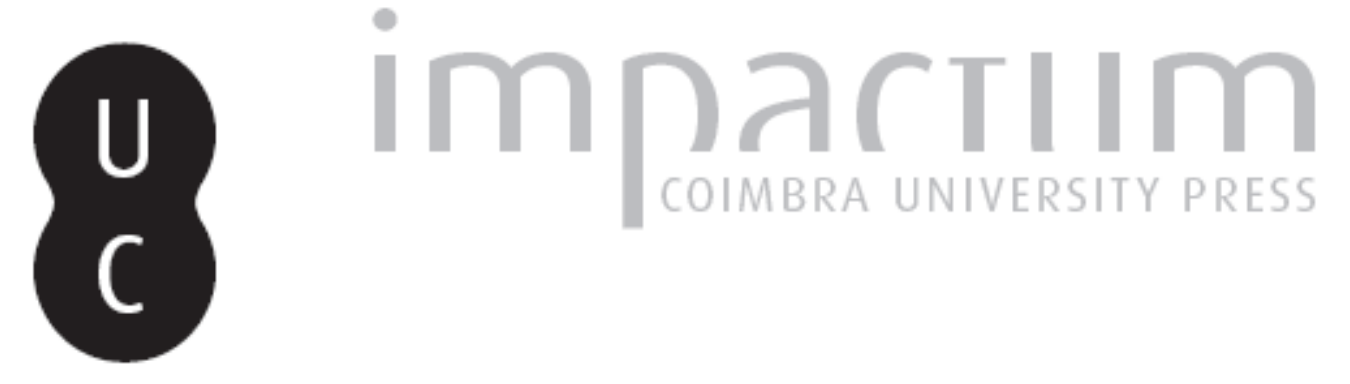

\title{
Importante compilação de trabalhos sobre o vulcão dos Capelinhos
}

\section{Autor(es): Rebelo, Fernando}

Publicado por: Associação Portuguesa de Riscos, Prevenção e Segurança

URL persistente:

URI:http://hdl.handle.net/10316.2/40127

DOI:

DOI:https://doi.org/10.14195/1647-7723_6_9

Accessed : $\quad$ 26-Apr-2023 07:29:46

A navegação consulta e descarregamento dos títulos inseridos nas Bibliotecas Digitais UC Digitalis, UC Pombalina e UC Impactum, pressupõem a aceitação plena e sem reservas dos Termos e Condições de Uso destas Bibliotecas Digitais, disponíveis em https://digitalis.uc.pt/pt-pt/termos.

Conforme exposto nos referidos Termos e Condições de Uso, o descarregamento de títulos de acesso restrito requer uma licença válida de autorização devendo o utilizador aceder ao(s) documento(s) a partir de um endereço de IP da instituição detentora da supramencionada licença.

Ao utilizador é apenas permitido o descarregamento para uso pessoal, pelo que o emprego do(s) título(s) descarregado(s) para outro fim, designadamente comercial, carece de autorização do respetivo autor ou editor da obra.

Na medida em que todas as obras da UC Digitalis se encontram protegidas pelo Código do Direito de Autor e Direitos Conexos e demais legislação aplicável, toda a cópia, parcial ou total, deste documento, nos casos em que é legalmente admitida, deverá conter ou fazer-se acompanhar por este aviso.

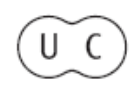




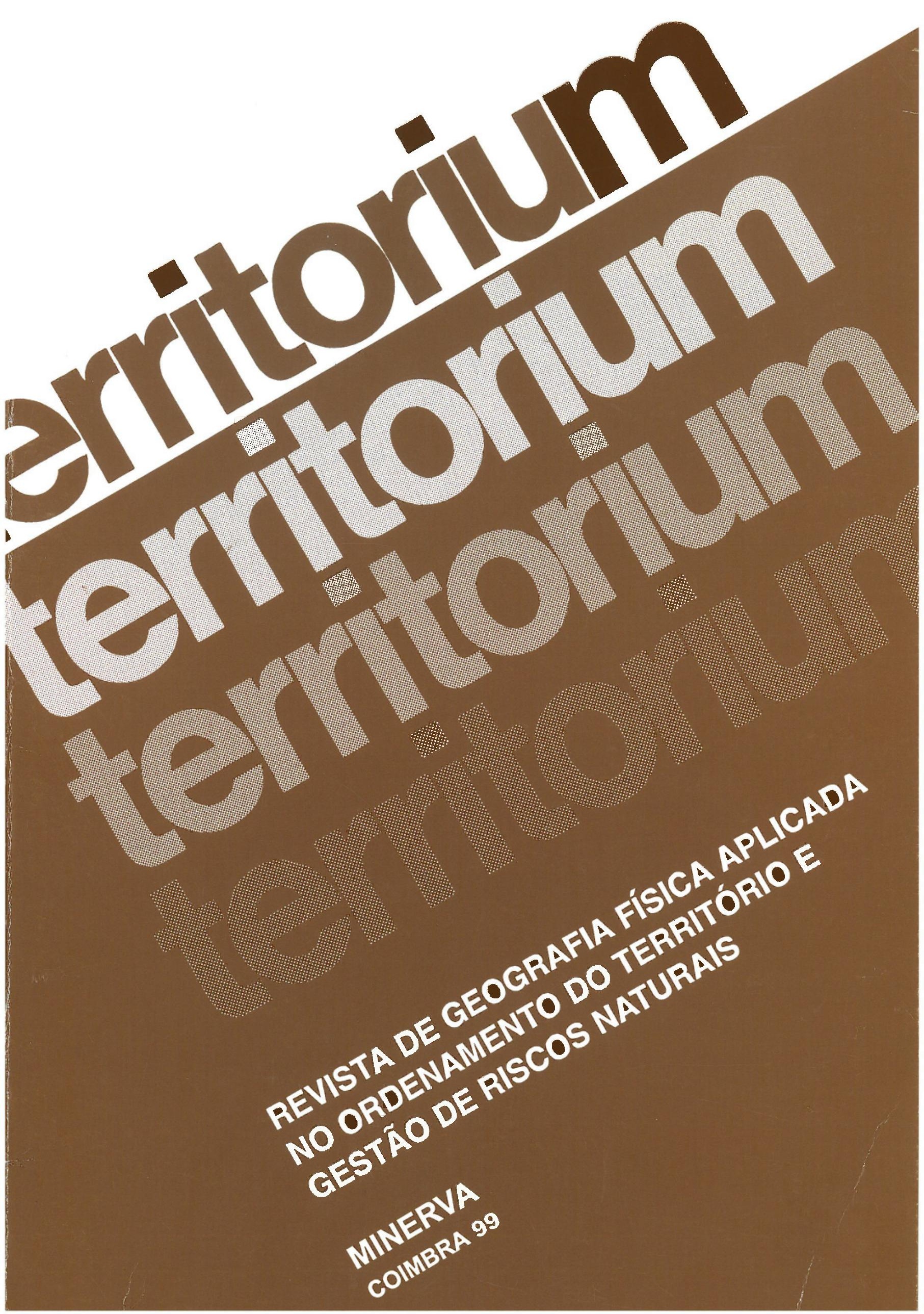




\title{
Importante compilação de trabalhos sobre o Vulcão dos Capelinhos
}

\author{
Fernando Rebelo
}

Vulcão dos Capelinhos. Retrospectivas (volume I) é o título de um livro com 259 páginas editado por Victor Hugo Forjaz e publicado em Ponta Delgada pelo Observatório Vulcanológico e Geotérmico dos Açores. Datado de 1997, só recentemente apareceu nos escaparates das livrarias.

Bastante sugestiva é a fotografia a cores de uma belíssima erupção. Todavia, a preto e branco, nos trabalhos publicados, são muitas as fotografias mostrando pormenores do que aconteceu nos Capelinhos entre 27 de Setembro de 1957 e 24 de Outubro de 1958 - uma actividade vulcânica notável que foi sendo estudada à medida que se processava e que levou à elaboração de vários trabalhos científicos, alguns dos quais reproduzidos neste livro que é dedicado ao Doutor Engenheiro Frederico Machado.

O editor assina logo a abrir uma "Introdução (Recordações...)", a que acrescenta alguns versos de Natália Correia e três fotografias - uma do princípio das erupções, outra, do conjunto da forma que existia um ano depois e uma terceira do que restava dela "quase quarenta anos após o início da actividade" (1997).

Segue-se o trabalho de FREDERICO MACHADO, "Actividade vulcânica da Ilha do Faial (1957-58)", que tinha sido publicado na revista Atlântida (Angra do Heroismo), vol. II, 1958 e vol. III, 1959. VICTOR HUGO FORJAZ apresenta seguidamente o seu trabalho "Actividade vulcânica da Ilha do Faial (1959-64)", que tinha vindo a lume na Atlântida, 6 (6), 1962, no Boletim do Museu e Laboratório Min. e Geol. da Fac. Ciências de Lisboa, 9 (2), 1963 e no Boletim da Sociedade Portuguesa de Ciências Naturais, 1964. Ainda de VICTOR HUGO FORJAZ, mas também assinado por N. MONTEIRO FERNANDES é o artigo "Evolução térmica e topográfica de 1964 a 1967", que já havia sido publicado em 1968.

A "Erosão marinha no cone vulcânico dos Capelinhos" e o "Cone dos Capelinhos em 1981" são os artigos seguintes, ambos da autoria de FREDERICO MACHADO e J. TÉRCIO FREIRE, o primeiro já publicadona Atlântida em 1976, o segundo na Açoreana em 1982.

Vem depois um artigo extraído do Bulletin de la Société Belge de Géologie, 67 (1), 1958-de HAROUN TAZIEFF, "L'Éruption 1957-1958 et la Tectonique de Faial (Açores)"
Seguem-se vários trabalhos extraídos da Memória 9 (nova série) dos Serviços Geológicos de Portugal, 1962. Um é de FREDERICO MACHADO, "Sobre o mecanismo da erupção dos Capelinhos", outro é de G. ZBYSZEWSKI e O. da VEIGA FERREIRA e intitula-se "Compte Rendu de deux visites au volcan de Capelinhos (Açores) après son eruption", outro ainda é de A. F. RICHARDS, J. B. HERSEY e W. T. MCGUINNESS, com o título de "Acoustic studies at Capelinho Volcano, Azores". Extraído ainda dessa Memória dos Serviços Geológicos é o "Relatório da Missão Técnica do Ministério das Obras Públicas para remediar as primeiras consequências da erupção vulcânica da Ilha do Faial", assinado por V.CAMPOS, F. MACHADO e J. A. S. GARCIA, e "A erupção dos Capelinhos - seus reflexos na economia da Ilha do Faial", de J. CORREIA DA CUNHA.

O livro termina com um conjunto documental de 44 fotografias a cores, com as cartas vulcanológicas da Itha do Faial nas escalas de 1:25000 e de 1:15000 e com o Curriculum Vitae do homenageado.

Outros trabalhos sobre os Capelinhos foram publicados. ORLANDO RIBEIRO e RAQUEL SOEIRO DE BRITO, por exemplo, escreveram sobre o que viram e o que puderam acompanhar no local durante o tempo da erupção; esse estudo, também muito interessante, foi publicado na Naturalia, mas é pouco conhecido; este facto poderá vir a ser ultrapassado se, no segundo volume destas Retrospectivas, o artigo em causa vier a ser incluido.

Em termos do estudo de riscos esta obra merece grande destaque. Começando embora pela análise de uma importante crise, a erupção dos Capelinhos em 1957-58, ela mostra claramente a situação de risco vulcanológico que se vive nos Açores, em geral, e na Ilha do Faial, em particular. Os outros riscos associados, com maior ou menor ligação com as vulnerabilidades, estão igualmente enunciados através da análise das consequências da crise. Numa época em que a terminologia científica não incluia as noções de risco, perigo e crise, não seria de esperar que os artigos apresentados estivessem escritos nessa perspectiva. Terá, portanto, de ser o leitor, com os seus conhecimentos actuais da teoria do risco, que deverá tirar partido dos muitos ensinamentos que esta autêntica antologia the oferece. 